\section{TOPICAL AND NEWSWORTHY} ITEMS

\section{NHS screening change 'would cut smears'}

Professor Peter Sasieni, a Cancer Research UK scientist at Queen Mary, University of London, has suggested that women would need far fewer smears if the National Health Service (NHS) switched to a new way of screening for cervical cancer. "With good uptake of the human papillomavirus (HPV) vaccine we can now start to move away from conventional testing", said Professor Sasieni. The new type of check tests for HPV, subtypes of which are known to be associated with cervical cancer. "Girls who have already had the jab would only need the new type of smear test twice in their lifetime and unvaccinated women would halve their number of checks from 12 to 6", he said.

Source: www.bbc.co.uk/health

\section{Contraceptive gel}

A novel form of contraceptive gel was presented at the American Society for Reproductive Medicine meeting in Denver, CO, USA in October 2010. The research has been carried out by The Population Council, a non-profit-making, non-governmental organisation. The gel is applied once daily and delivers hormones transcutaneously. The trials have shown a reduction in side effects such as headaches, temporary weight gain and acne. It is also suitable for breastfeeding mothers. The active ingredients are nestorone, a synthetic progestogen and a form of oestrogen chemically identical to natural oestrogen. The study involved 18 subjects. Further research will establish whether this method can be widely used.

For more information contact: pubinfo@popcouncil.org.

\section{Diabetes DVD urges women to plan for pregnancy}

With women with diabetes are five times more likely to have a stillborn baby than other women. Researchers at Queen's University Belfast have produced a new DVD to encourage all women with the condition to plan for pregnancy. Women with Diabetes: Things You Need to Know (But Maybe Don't) raises awareness about important reproductive health issues for women with diabetes. Dr Valerie Holmes, who led the project, commented: "It is important that women with diabetes are aware of the importance of planning their pregnancy. Almost all women with diabetes can have healthy babies if good pre-pregnancy blood glucose control is achieved." As well as raising awareness of the importance of reproductive health issues, such as avoiding unplanned pregnancy, the DVD provides guidance about preconception care for those women planning a pregnancy. The DVD has been put together by women with diabetes. They were filmed as 'the cast', sharing their stories, views and experiences along with commentary that gives the relevant research evidence.
Babies born to women with diabetes are more likely to be affected by congenital anomalies, including spina bifida, heart and kidney anomalies, risks which can be reduced by good blood glucose control. As part of this project, diabetes health care teams throughout Northern Ireland will be provided with copies of the DVD for distribution to all women with diabetes of childbearing age.

For more information contact: Donna McCullough. Tel: +44 (0)28 90975391.

\section{Pope says condoms "sometimes okay"}

Pope Benedict XVI has suggested that condoms may be helpful to stop the spread of HIV, saying male prostitutes who use condoms may be beginning to act responsibly. He was interviewed by a German journalist for a book entitled Light of the World: The Pope, The Church and The Signs of the Times, published at the end of November 2010. Previously, the pontiff has blamed condoms for making the AIDS crisis worse. The Vatican has come under pressure even from church officials to condone condom use for such monogamous married couples to protect the uninfected spouse from transmission.

Source: The Guardian, Sunday 21 November 2010

\section{Submitted by Henrietta Hughes}

General Practitioner, London, UK

J Fam Plann Reprod Health Care 2011;37:58. doi:10.1136/ffprhc.2010.0020 